\title{
Sero-prevalence and associated risk factors of Toxoplasma gondii infection among pregnant women attending Omdurman friendship hospital, Omdurman
}

\author{
Wahaj M Mohammed ${ }^{1}$, Abdalla HS ${ }^{2}$, Satti AB ${ }^{3}$, Tagwa B Mustafa ${ }^{3}$ and Ahmed S Kabbashi ${ }^{*}$ \\ ${ }^{1}$ Department of Parasitology, Faculty of Medical Laboratory Sciences, International University of Africa, Khartoum, Sudan \\ ${ }^{2}$ Department of Parasitology, Faculty of veterinary, University of Khartoum., Khartoum, Sudan \\ ${ }^{3}$ Department of Parasitology, Faculty of Medical Laboratory Sciences, Omdurman Islamic University, Omdurman, Sudan
}

\begin{abstract}
Background: Toxoplasmosis in pregnancy is associated with spontaneous abortions, low birth weight babies, congenital deformities and intrauterine deaths. In many developed countries, pregnant mothers are screened for infection with Toxoplasma gondii, the causative parasite, and treatment is offered early in order to prevent these complications. In most developing countries, including Khartoum, the burden and risk factors of T. gondii infection among pregnant women, thus making it difficult to plan and implement control measures.
\end{abstract}

Study Objectives: This study aimed at determining the prevalence of T. gondii infections and their risk factors among pregnant women attending antenatal care clinics in Kigali, Rwanda.

Methods: This was a cross-sectional descriptive study involving 384 pregnant women aged 18 years and above who were attending antenatal Omdurman friend ship hospital, between April 2015- May 2017.

Venous blood samples were collected from study participants and screened for IgG and IgM antibodies against T. gondii using the ELISA technique. The participants were also interviewed about selected behaviors that predispose individuals to infections with T. gondii.

Results: Out of the 300 surveyed pregnant women, 65(21.7\%) serum samples were found to have IgG while IgM was showed only 3(1\%) IgM. Surveyed populations were divided into four age groups: (up to 20 years), (21-30), (31-40 years) and (more than 40 years). The positive cases within each age group showed IgM in one $(0.3 \%)$, one $(0.3 \%)$, one $(0.3 \%)$ and $0(0 \%)$ respectively. On the other hand IgG was detected in $9(3 \%), 36(12 \%), 19(6.3 \%)$ and one $(0.3 \%)$ respectively. Exposure to cats has been considered a major risk factor for acquisition of infection [1]. In the present study, it appears that cats have no direct role in transmission of the disease and there is no stastistically association between cat contact and infection ( $\mathrm{P}=0.88$ and 0.1 with $\mathrm{IgM}$ and $\mathrm{IgG}$ respectively).Also meat consumption has no role in disease transmission as no statistically association women with previous history of miscarriage in the study group showed T. gondii sero- prevalence rate of 42 and 3 using ELISA IgG and IgM respectively compared to 23 and 0 among others with no past history of miscarriage with no significant difference between them (P $=0.76$ and 0.18$)$ respectively.

Conclusion: The seroprevalence of $T$. gondii antibodies is relatively low among the pregnant women. Undercooked meat consumption and cat contact are not significantly associated with sero-prevalence of anti-T. gondii $\operatorname{IgG}$ and $\operatorname{IgM}$ among the pregnant women.

\section{Introduction}

T. gondii is an obligate intracellular protozoan parasite that causes toxoplasmosis [2]. It is estimated that about one third of the world's population is infected with T. gondii [3]. In Africa, overall seroprevalence rate as high as $92.5 \%$ has been reported [4]. However, the prevalence of infection varies widely between countries (ranging between 10 and $80 \%$ ) and often within a given country or between different communities in the same region [3]. However, in most developing countries including Sudan, the prevalence of toxoplasmosis is largely unknown. In the immunocompetent Toxoplasma infection is often asymptomatic, and frequently results in the chronic persistence of cysts within host tissues, that probably lie dormant for life $[5,6]$. High prevalence of the infection have been reported among pregnant women and women of childbearing age from different foci in Latin America, parts of Eastern/ Central Europe, the Middle East, parts of south-east Asia and Africa [3]. This can lead to congenital toxoplasmosis, which is a serious disease that is associated with severe congenital deformities and intrauterine deaths especially when the infection is acquired early in pregnancy [7]. Control of congenital toxoplasmosis is therefore important and, in the developed countries, includes screening of pregnant mothers for infection. Most studies on prevalence of T. gondii infections have relied on antibody detection. Although, antibody detection is associated with false positives. A more reliable way of diagnosing active infection is the use of molecular techniques such as PCR for diagnosing active infection using blood, brain biopsy, and liver biopsy [8-10]. However, this technique is very expensive and not easily available in most developing

*Correspondence to: Ahmed S Kabbashi, Department of Parasitology, Faculty of Medical Laboratory Sciences, International University of Africa, Khartoum Sudan, E-mail: ahmedsak88@gmail.com

Key words: Sero-prevalence, Toxoplasmosis (Toxoplasma gondii), Omdurman, Sudan Received: February 05, 2018; Accepted: February 15, 2018; Published: February 18,2018 
countries making its use in routine diagnosis not feasible. It is for this reason that diagnosis of toxoplasmosis in most health facilities in these countries still largely rely on serology, and this is the method of diagnosis that was used in this study for purposes of being realistic with what is done in the field. In line with this, the present study sought to determine the seroprevalence of $T$. gondii infections among pregnant women attending selected antenatal clinics in omdurman, using ELISA tests and risk factors associated with the acquisition of toxoplasmosis.

\section{Material and methods}

\section{The Study area and population}

The study was conducted in Khartoum state targeting the pregnant women attending Omdurman friendship hospital. The targeted women were categorized according to age groups (15- 20, 21-30, 31-40 and 4045 year) and stage of pregnancy ( $1^{\text {st }}, 2^{\text {nd }}$ and $3^{\text {rd }}$ trimesters $)$.

Study design: This was a cross-sectional descriptive study involving pregnant women attending antenatal care at selected health centers. Each participant was interviewed in private to promote confidentiality. Furthermore, no names were used on any data collection forms. Instead, each study participant was given a unique identifying number. Venous blood samples were drawn from each study participant.

Sample size: The minimum sample size for the study was calculated using the following formula given by Fischer et al. [11]. Sample size calculation according to Fischer's formula.

Data collection and analysis: After obtaining informed consent, the study participants were interviewed by administration of a standard questionnaire to obtain the socio-demographic and economic status information as well as epidemiological risk factors. The influential risk factors considered in the study included maternal age, gestation period, contact with cats, and cooking and eating habits such as: eating raw or undercooked meat. Laboratory results from the tests were entered using the same number as the one on the questionnaires. All the data were then entered into Excel spreadsheet and later exported into SPSS for statistical analysis.

Collection of sample: About $5 \mathrm{~mL}$ of venous blood were collected aseptically from each of the 300 pregnant women. All specimens were transported to the laboratory where serum was separated from the blood by centrifugation at 3,000 rpm for 5 minutes. Serum samples were numbered and tested for anti-T. gondii antibodies (IgM and IgG) using ELISA assays.

\section{Methods}

TOXO IgG- IgM: Ten microliters of plasma sample was diluted using $1000 \mu \mathrm{l}$ of sample diluent. The diluted specimen was then incubated in T. gondii antigen-coated wells at $370 \mathrm{C}$ for 1 hour. The wells were then washed with washing solution to remove residual test specimen. Enzyme-labeled antibodies to human IgG -IgM (conjugate) were then added. After another washing using washing solution to eliminate unbound material an enzyme substrate solution containing a chromogen was added. This solution developed a blue colour if the sample contained anti-T. gondii IgG and anti-T. gondii IgM. The blue colour then changed to yellow after blocking the reaction with sulphuric acid. The intensity of the colour which is proportional to the amount of anti-T. gondii IgG-IgM in the test specimen was read using an ELISA reader at $450 \mathrm{~nm}$ wavelength. The concentration of antibodies in the sample was then determined by mean of a calibration curve.

\section{Result and discussion}

Few studies have looked at sero-prevalence of anti-T. gondii in Sudan. The present study showed an overall seroprevalence of anti- $T$. gondii antibody among pregnant women in Omdurman friendship, to be $22.6 \%$. (Table 1). The result however, agreed with Musa (2014) who showed that $20.2 \%$ of pregnant women were positive for IgG. Some showed a high prevalence rate than the results obtained for example in Turkey $77 \%$ was recorded, and in Togo $75 \%$ were reported by Deniau et al. also the results obtained by Satti, 2011 showed that the prevalence was $38.9 \%$ by ELISA IgG in Khartoum state; also Khalil (2014) was found $73.1 \%$ by using ELISA IgG in rural areas in Sudan. It may also disagree with result obtained in 2006 by Maha et al. who showed that the prevalence using ELISA was $35.1 \%$ positive IgG antibodies to $T$. gondii in Sudanese pregnant women. Regional variation of seroprevalence of $T$. gondii infection has previously been described [1]. The reason for this may not be clear but could include several factors such as socio-economic status, education, sanitary conditions and differences in dietary habits. The fact that the study population had some individuals with IgM (1\%) antibodies implies that transmission of $T$. gondii infection had either taken place during the pregnancy or the women had become pregnant shortly after acquiring $T$. gondii infection. Although the prevalence of acute infection was low at $1 \%$, this is still an important finding since there is a risk of these women transmitting the infection to their unborn child thereby resulting in congenital toxoplasmosis, which is a more severe disease that may not only lead to abortion but also to congenital malformations in the new born, the results indicated that the higher rate was encountered in the age group of 21-30 years, followed by the next group 31-40 years. approximately, corresponds with the age group 26-30 years previously reported by Khalil et al. [12] and disagree with the results revealed by AL-Dahmoshi et al. [13] in Iraq that the age group ranged from 14-24 years was more infected with toxoplasmosis (Table 2). In the present study, it appears that cats have no direct role in transmission of the disease and there is no stastistically association between cat contact and infection $(\mathrm{P}=0.88$ and 0.1 with $\operatorname{IgM}$ and $\operatorname{IgG}$ respectively). However, several studies have concluded that exposure to cats increased the risk of T.gondii seropositivity, other studies found no association [1419]. Exposure to cats is not sufficient for transmission of T. gondii to women; infection in cats and personal hygiene should be evaluated. In Sudan the contact between people and cats is not as in Europe (Table 3). The role of consumption of raw meat in the acquisition of T. gondii infection has not always been clear. Several studies have found no association, although some studies have identified an association between eating raw meat and $T$. gondii seropositivity [1,16,20-26]. In this study, meat consumption has no role in disease transmission as no

Table 1. Prevalence according to IgG and IgM specific antibody for T. gondii using ELISA

\begin{tabular}{|c|c|c|c|}
\hline Type of immunoglobulin by ELISA & Total & Positive cases & Percentage (\%) \\
\hline IgG & 300 & 65 & $21.7 \%$ \\
\hline IgM & 300 & 3 & $1 \%$ \\
\hline
\end{tabular}

Table 2. prevalence of T.gondii immunoglobulin according to age groups

\begin{tabular}{|c|c|c|c|c|c|}
\hline Immunoglobulin by ELISA & \multicolumn{4}{|c|}{ Age group(years) } & Total \\
\hline & $15-20$ & $21-30$ & $31-40$ & $41-45$ & \\
\hline $\operatorname{IgM}$ & 1 & 1 & 1 & 0 & 3 \\
\hline IgG & 9 & 36 & 19 & 1 & 65 \\
\hline
\end{tabular}

Table 3. Antitoxoplasma antibodies in pregnant women who had contact with cats

\begin{tabular}{|c|c|c|c|}
\hline Cat contact & Number examined & IgG positive & IgM positive \\
\hline Yes & 153 & $39(25.5 \%)$ & $3(2 \%)$ \\
\hline No & 147 & $26(17.7 \%)$ & $0(0 \%)$ \\
\hline
\end{tabular}


Table 4. Anti Toxopasmal antibodies (IgM, IgG) in pregnant women who consume raw meat using ELISA

\begin{tabular}{|c|c|c|c|c|}
\hline $\begin{array}{c}\text { Consuming raw } \\
\text { meat }\end{array}$ & $\begin{array}{c}\text { Number } \\
\text { examined }\end{array}$ & IgG positive & IgM positive & $\boldsymbol{p}$ value \\
\hline Consume & 123 & $32(26 \%)$ & $1(0.8 \%)$ & 0.127 \\
\hline Not Consume & 177 & $33(18.6 \%)$ & $2(1.1 \%)$ & 0.786 \\
\hline
\end{tabular}

statistically association that may due to people recently stop that habbit of eating raw or uncooked meat (Table 4).

\section{Conclusion}

As a general conclusion, it can be stated that the frequency of specific IgM and IgG antibodies using ELISA is considered high among pregnant women investigated for Toxoplasmosis. The absence of a statistically significant relationship between the prevalence of Toxoplasma infection among pregnant women and contact with cats and consumption of raw meat.

\section{References}

1. Weigel RM, Dubey JP, Dyer D, Siegel AM (1999) Risk factors for infection with Toxoplasma gondii for residents and workers on swine farms in Illinois. Am J Trop Med Hyg 60: 793-798. [Crossref]

2. Jones JL, Kruszon-Moran D, Wilson M, McQuillan G, Navin T, et al. (2001) Toxoplasma gondii infection in the United States: seroprevalence and risk factors. $\mathrm{Am}$ J Epidemiol 154: 357-365. [Crossref]

3. Pappas G, Roussos N, Falagas ME (2009) Toxoplasmosis snapshots: global status of Toxoplasma gondii seroprevalence and implications for pregnancy and congenital toxoplasmosis. Int J Parasitol 39: 1385-1394. [Crossref]

4. Ayi I, Edu SA, Apea-Kubi KA, Boamah D, Bosompem KM, et al. (2009) Seroepidemiology of toxoplasmosis amongst pregnant women in the greater accra region of ghana. Ghana Med J 43: 107-114. [Crossref]

5. Studenicová C, Bencaiová G, Holková R (2006) Seroprevalence of Toxoplasma gondii antibodies in a healthy population from Slovakia. Eur J Intern Med 17: 470-473. [Crossref]

6. Malla N, Sengupta C, Dubey ML, Sud A, Dutta U (2005) Antigenaemia and antibody response to Toxoplasma gondii in human immunodeficiency virus-infected patients. $\mathrm{Br}$ J Biomed Sci 62: 19-23. [Crossref]

7. Chen KT, Eskild A, Bresnahan M, Stray-Pedersen B, Sher A, et al. (2005) Previous maternal infection with Toxoplasma gondii and the risk of fetal death. Am J Obstet Gynecol 193: 443-449. [Crossref]

8. Dupouy-Camet J, de Souza SL, Maslo C, Paugam A, Saimot AG, et al. (1993) Detection of Toxoplasma gondii in venous blood from AIDS patients by polymerase chain reaction. J Clin Microbiol 31: 1866-1869. [Crossref]

9. Filice GA, Hitt JA, Mitchell CD, Blackstad M, Sorensen SW (1993) Diagnosis of Toxoplasma parasitemia in patients with AIDS by gene detection after amplification with polymerase chain reaction. J Clin Microbiol 31: 2327-2331. [Crossref]
10. Cristina N, Pelloux H, Goulhot C, Brion JP, Leclercq P, et al. (1993) Detection of Toxoplasma gondii in AIDS patients by the polymerase chain reaction. Infection 21 : 150-153. [Crossref]

11. Nigel B, Pope D, Stanistreet D (2008) Quantitative Methods for Health Research England: John Wiley \& Sons Ltd.

12. Khalil Mohamed, Aziz A Ahmed, Intisar ER (2013) Prevalence and risk factors for Toxoplasma gondii infection in humans from Khartoum State, Sudan. Int J Pub Hlth Epid 2: 60-66.

13. Al-Dahmoshi H, Al-Mammori R, Shareef H, Al-Khafagee S (2013) Study of IL-8 and IL-17 levels among certain group of repeated spontaneous abortion women with or without Toxoplasmosis, Iraq. Int Res J Biolo Scien 2: 37-41.

14. McCulloch W, Braun J, Heggen D, Top F (1963) Studies on medical and veterinary students skin tested for toxoplasmosis. Public Health Rep 78: 689-698. [Crossref]

15. Etheredge GD, Frenkel JK (1995) Human Toxoplasma infection in Kuna and Embera children in the Bayano and San Blas, eastern Panama. Am J Trop Med Hyg 53: 448457. [Crossref]

16. Buffolano W, Gilbert RE, Holland FJ, Fratta D, Palumbo F, et al. (1996) Risk factors for recent toxoplasma infection in pregnant women in Naples. Epidemiol Infect 116 347-351. [Crossref]

17. Fisher S, Reid RR (1973) Antibodies to Toxoplasma gondii and contact with animals in the home. Med J Aust 1: 1275-1277. [Crossref]

18. Nissapatorn V, Kamarulzaman A, Init I, Tan LH, Rohela M, et al. (2002) Seroepidemiology of toxoplasmosis among HIV-infected patients and healthy blood donors. Med J Malaysia 57: 304-310. [Crossref]

19. Ertug S, Okyay P, Turkmen M, Yuksel H (2005) Seroprevalence and risk factors for Toxoplasma infection among pregnant women in Aydin province, Turkey. BMC Public Health 5: 66. [Crossref]

20. Peterson DR, Tronca E, Bonin P (1972) Human toxoplasmosis prevalence and exposure to cats. Am J Epidemiol 96: 215-218. [Crossref]

21. Riemann HP, Meyer ME, Theis JH, Kelso G, Behymer DE (1975) Toxoplasmosis in an infant fed unpasteurized goat milk. J Pediatr 87: 573-576. [Crossref]

22. DiGiacomo RF, Harris NV, Huber NL, Cooney MK (1990) Animal exposures and antibodies to Toxoplasma gondii in a university population. Am J Epidemiol 131: 729733. [Crossref]

23. Seuri M, Koskela P (1992) Contact with pigs and cats associated with high prevalence of Toxoplasma antibodies among farmers. Br J Ind Med 49: 845-849. [Crossref]

24. Alvarado-Esquivel C, Sifuentes-Alvarez A, Narro-Duarte S, Estrada- Martinez S, DiazGarcia J, et al. (2006) Seroepidemiology of Toxoplasma gondii infection in pregnant women in a public hospital in northern Mexico. BMC Infect Dis 6: 113. [Crossref]

25. Cook AJ, Gilbert RE, Buffolano W, Zufferey J, Petersen E, et al. (2000) Sources of Toxoplasma infection in pregnant women: European multicentre case-control study. European Research Network on Congenital Toxoplasmosis. Brit Med J 321: 142-147. [Crossref]

26. Konishi E, Takahashi J (1987) Some epidemiological aspects of Toxoplasma infections in a population of farmers in Japan. Int J Epidemiol 16: 277- 281. [Crossref]

Copyright: (C2018 Mohammed WM. This is an open-access article distributed under the terms of the Creative Commons Attribution License, which permits unrestricted use, distribution, and reproduction in any medium, provided the original author and source are credited. 